\title{
A prospective case control study of the effects of oligohydramnios on fetomaternal outcome in mothers with term pregnancy in a rural medical college
}

\author{
Dipak Mandi*, Sayantan Sen, Vasundhara Goswami
}

Department of Obstetrics and Gynecology, Burdwan Medical College and Hospital, Burdwan, West Bengal, India

Received: 12 September 2018

Accepted: 06 October 2018

*Correspondence:

Dr. Sayantan Sen,

E-mail: sayantan.sen88@gmail.com

Copyright: () the author(s), publisher and licensee Medip Academy. This is an open-access article distributed under the terms of the Creative Commons Attribution Non-Commercial License, which permits unrestricted non-commercial use, distribution, and reproduction in any medium, provided the original work is properly cited.

\begin{abstract}
Background: The aim of the current study was to assess the fetomaternal effects of oligohydramnios on term pregnancies in a rural tertiary care setup.

Methods: A perspective case control hospital-based trial was conducted at Burdwan Medical College and Hospital for a period of one year. Pregnancies at term (37-42 weeks) were included in the study. 103 patients with sonographically diagnosed oligohydramnios were included in the case group. The control group comprised of 103 mothers at term with normal liquor volume. Demographic data and fetomaternal outcome parameters were assessed and compared.

Results: There was increased incidence of fetal and perinatal complications including low birth weight, birth asphyxia and NICU admission. There were more perinatal deaths in the case group compared to the control group. Induction of labour, operative delivery, meconium stained liquor and incidence of preeclampsia were also increased in mothers with low AFI.

Conclusions: Oligohydramnios is associated with an increased risk of labour and perinatal complications. Adequate antenatal surveillance and intranatal monitoring coupled with correction of underly-ing factors is the mainstay of management.
\end{abstract}

Keywords: Maternal outcome, Oligohydramnios, Perinatal outcome, Term pregnancy

\section{INTRODUCTION}

Amniotic fluid (AF) has various functions during pregnancy. It protects the fetus against trauma, allows space for fetal movement, enables fetal swallowing (necessary for gastrointestinal tract development) and prevents cord compression. ${ }^{1}$

In early pregnancy it is an ultra-filtrate of maternal plasma. In the 2nd trimester, it consists of extracellular fluid that diffuses across fetal skin. After 20 weeks, skin cornification occurs and AF is composed mainly of fetal urine. The importance of amniotic fluid volume as an indicator of fetal wellbeing has made its assessment an important part of antenatal fetal surveillance. ${ }^{2}$

The quantity of amniotic fluid at any time in gestation is the product of water exchange between the mother, fetus, and placenta, and is maintained within a relatively narrow range. Disorders of this regulatory process can lead to extremes of liquor volumes resulting in adverse pregnancy outcomes.

The American College of Obstetricians and Gynaecologists has defined oligohydramnios as amniotic fluid index (AFI) $\leq 5$ ( $<10$ th centile) or maximum 
vertical pocket devoid of umbilical cord or fetal limbs measuring $<2 \mathrm{~cm} .{ }^{3}$ It is a common obstetric complication occurring in $3-5 \%$ pregnancies at term. ${ }^{4}$ Phelan et al had described the semiquantitative method of measuring amniotic fluid index which is the sum of deepest pockets of the four quadrants. ${ }^{5}$

The risk factors for oligohydramnios are fetal chromosomal or structural anomalies (renal anomalies), rupture of the membrane, intrauterine infection, use of certain drugs (PG inhibitors, ACE inhibitors), postmaturity, intrauterine growth restriction and hypertensive disorders. $^{6}$ In fact any cause of uteroplacental insufficiency can lead to reduce AF.

There are several complications of reduced AF. Some of these are related to the causes of oligohydramnios while the others are due to the reduced liquor itself. Some of the complications are fetal pulmonary hypoplasia, deformities, still birth, perinatal asphyxia, cord compression and increased operative interference. However certain studies have found no significant correlation between isolated decreased AF and adverse pregnancy and perinatal outcomes. ${ }^{7-9}$

The management depends on the underlying cause, gestational age and associated complications. In term pregnancies, the strategy is to assess fetomaternal wellbeing (BPP, colour doppler), manage complications and ultimately deliver the fetus. Amnio infusion is generally not recommended and is reserved for those cases which have secondary umbilical cord compression due to decreased liquor.

The present study aims to compare pregnancies at term with and without sonographically diagnosed oligohydramnios using maternal, fetal and perinatal outcome parameters.

\section{METHODS}

After obtaining clearance from Clinical Research Ethics Committee, Burdwan Medical College and Hospital, this prospective case control study was conducted from March 2017 to February 2018 in the department of Gynaecology and Obstetrics, Burdwan Medical College and Hospital, Bardhaman, West Bengal, India.

This study was conducted with full compliance to the declaration of Helsinki 2013. ${ }^{10}$ The informed consent for participation in the study was obtained from the subjects whose age was above 18 years (considered adult in India). Where age of the subject was $<18$ years, consent was obtained both from the subject and their legal guardian. The aim and procedure of the study was described to the subjects in detail. Those who did not give consent were excluded.

Subjects were recruited from the antenatal clinic and ward of the Department of Obstetrics and Gynaecology,
Burdwan Medical College and Hospital. Those who accurately remembered their last menstrual period or had first trimester dating scans and were at term (37-42 weeks gestational age) were considered. Pregnancies at $<37$ weeks and $>42$ weeks were excluded. Obstetric ultrasound (USG) was performed by a radiologist and those with AFI $<5$ were included in the study group. Term pregnancies with AFI 6-24 were kept in the control group. A total of 103 mothers were recruited in the study group and 103 in the control group.

Those with fetal congenital anomalies were excluded as these had separate effects on fetal outcome and changed the management scheme and had to be delivered immediately. Multifetal and post caesarean pregnancies were also excluded.

After admission, comprehensive history taking and clinical examination were performed to assess causative factors and associated complications. History regarding antenatal drug intake was taken.

Blood pressure measurement, urinary protein estimation and laboratory parameters were used to detect hypertensive disorders. Ultrasound examination was performed to confirm amniotic fluid status, placental localization, fetal lie, presentation and presence of growth restriction.

Doppler study was performed to assess umbilical (UA) and middle cerebral artery (MCA) status. Biophysical profile (BPP) was done to ascertain whether fetal neurohormonal and central nervous system were intact. Patients with normal doppler and BPP were followed up every two weeks and allowed to go into labour spontaneously.

Those with deranged parameters (absent or reversed flow in UA) were either induced or planned for caesarean section depending on gestational age and associated complications. Induction of labour was done by either oxytocin infusion or Dinoprostone intracervical gel (PGE2).

High dose oxytocin was used according to standardized protocols (4-6 mU/min increased at a rate of 4-6 $\mathrm{mU} / \mathrm{min}$ at 30 mints interval to maximum of $30 \mathrm{mU} / \mathrm{min}) .{ }^{11} \mathrm{High}$ dose oxytocin has been shown to reduce labour duration without having significant adverse neonatal effects. ${ }^{12}$

Dinoprostone gel was used as per ACOG guidelines. ${ }^{13}$ Intracervical gel containing $0.5 \mathrm{mg}$ PGE2 was given at 6 hours interval up to a maximum of 3 doses in 24 hours. Patients with associated placenta previa, cephalopelvic disproportion and failed induction of labour, were terminated by caesarean section. Cardiotocography (CTG) was done on all patients in labour.

After delivery, thorough examination of the newborn was done by the on duty paediatrician. Parameters such as 
APGAR score, birth weight, and need for neonatal intensive care unit (NICU) admission were noted.

\section{Statistical analysis}

Statistical analysis was carried out in Graph pad prism version 6.01 (Graph pad Software, La Jolla, CA, USA). Continuous variables were tested for normal distribution by the Kolmogorov-Smirnov test. Parametric data were expressed as mean and standard deviation (SD) and analyzed by independent $\mathrm{T}$ test and Anova test. A P value $<0.05$ was considered as significant, statistically.

\section{RESULTS}

The demographic characteristics of the two groups showed no significant differences in age and residential area.

However, unbooked cases were found to have a significantly higher incidence of oligohydramnios compared to the booked patients.

Table 1: Demographic details of the study subjects in the two groups.

\begin{tabular}{|c|c|c|c|}
\hline & $\begin{array}{l}\text { AFI }<5 \\
(n=103)\end{array}$ & $\begin{array}{l}\text { AFI 6-24 } \\
(\mathrm{n}=103)\end{array}$ & \multirow[t]{2}{*}{$\begin{array}{l}\mathbf{P} \\
\text { value }\end{array}$} \\
\hline & \multicolumn{2}{|c|}{ Number, Percentage } & \\
\hline \multicolumn{4}{|c|}{ Age group (years) } \\
\hline$<20$ & $57,55.34$ & $48,46.6$ & \multirow[t]{4}{*}{0.100} \\
\hline $21-25$ & $35,33.98$ & $39,37.86$ & \\
\hline $26-30$ & $8,7.77$ & $5,4.85$ & \\
\hline$>30$ & $3,2.91$ & $11,10.68$ & \\
\hline \multicolumn{4}{|c|}{ Booking status } \\
\hline Booked & $72,69.9$ & $85,82.52$ & \multirow[t]{2}{*}{0.033} \\
\hline Unbooked & $31,30.1$ & $18,17.48$ & \\
\hline \multicolumn{4}{|c|}{ Residential area } \\
\hline Rural & $96,93.20$ & $99,96.12$ & \multirow[t]{2}{*}{0.537} \\
\hline Urban & $7,6.80$ & $4,3.88$ & \\
\hline
\end{tabular}

Table 2 shows the maternal parameters of the study and control group. The gravida comparison be-tween the groups shows hardly any difference. 50 patients $(48.5 \%)$ in the study group had to be induced compared to only 21 $(20.4 \%)$ in the control group.

Out of these 50, a high percentage (74\%) underwent caesarean section due to failure of induction or other obstetric indications.

Among the mothers allowed spontaneous onset of labour, 25 had to be put up for caesarean section.

Compared to the control group, a significantly higher number of mothers had to be induced and among them a higher number had to be posted for caesarean section.
The number of mothers with moderate and thick meconium staining of liquor were significantly more in the case group (46 versus 4 ).

Also, patients with preeclampsia were more in the study group compared to the control group (44 versus 7).

Table 2: Maternal parameters of the study subjects in the two groups.

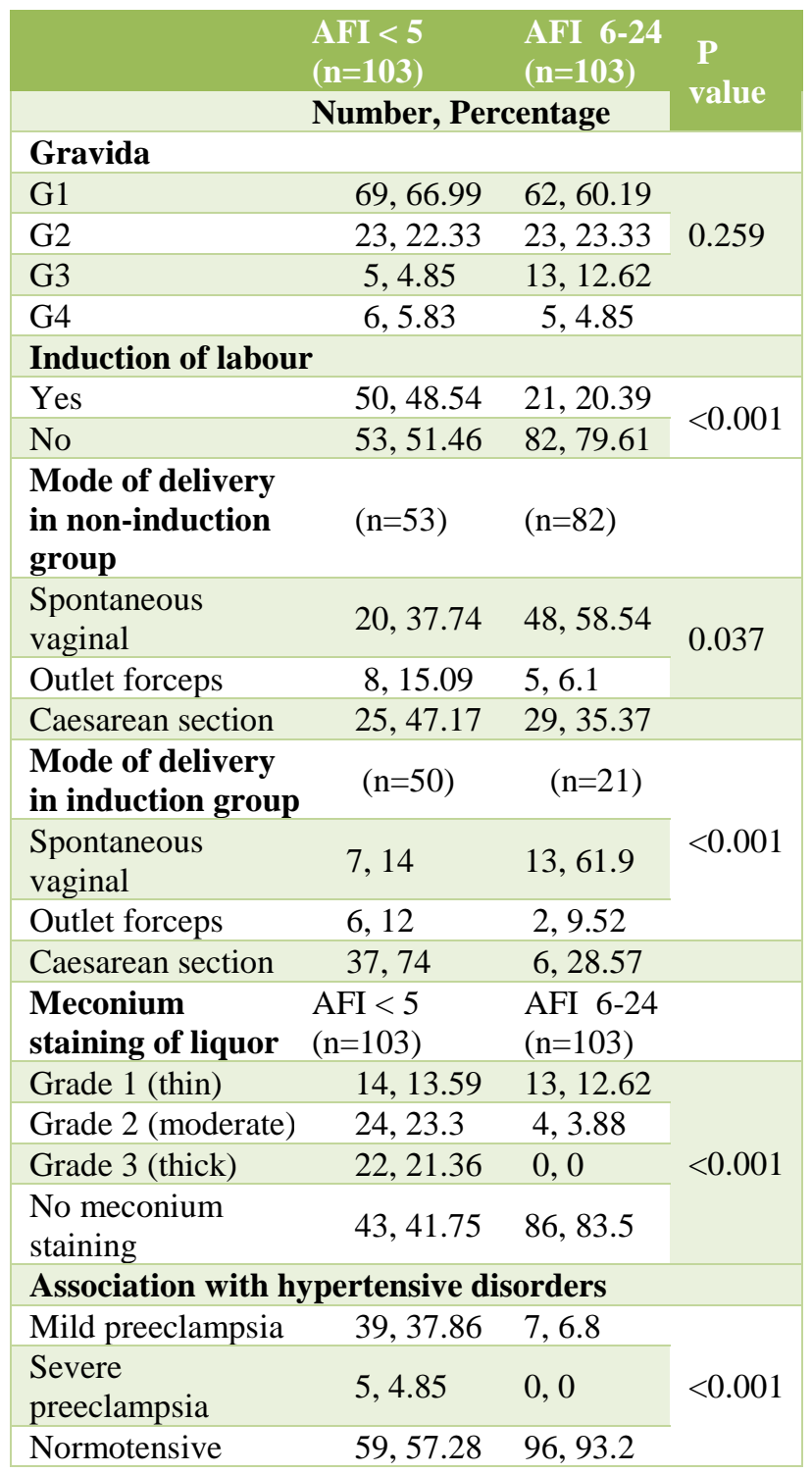

Table 3 shows the fetal and perinatal outcomes of the two groups. There were 3 cases of still birth in women with low AFI compared to none in the control group.

There was a significant difference in the birth weight between the groups with a notably high number of low birth weight newborns in the study group. Similarly, number of NICU admissions, perinatal deaths and birth ashyxia (AP-GAR < 7) were more in patients with low AFI. 
Table 3: Fetal and perinatal parameters in the two groups.

\begin{tabular}{|c|c|c|c|}
\hline & $\begin{array}{l}\text { AFI <5 } \\
(n=103)\end{array}$ & $\begin{array}{l}\text { AFI 6-24 } \\
(n=103)\end{array}$ & \multirow{2}{*}{$\begin{array}{l}P \\
\text { value }\end{array}$} \\
\hline & \multicolumn{2}{|c|}{ Number, Percentage } & \\
\hline \multicolumn{4}{|l|}{ Birth Weight } \\
\hline$<2 \mathrm{~kg}$ & $10,9.71$ & $3,2.91$ & \multirow{4}{*}{$<0.001$} \\
\hline $2-2.5 \mathrm{~kg}$ & $59,57.28$ & $25,24.27$ & \\
\hline $2.6-3 \mathrm{~kg}$ & $31,30.1$ & $57,55.34$ & \\
\hline$>3 \mathrm{~kg}$ & $3,2.91$ & $18,17.48$ & \\
\hline \multicolumn{3}{|l|}{ Still Birth } & \multirow{3}{*}{0.081} \\
\hline No & $100,97.09$ & 103,100 & \\
\hline Yes & $3,2.91$ & 0,0 & \\
\hline $\begin{array}{l}\text { 5-minute } \\
\text { APGAR score }\end{array}$ & $\begin{array}{l}\text { AFI < 5 } \\
(n=100)\end{array}$ & $\begin{array}{l}\text { AFI 6-24 } \\
(n=103)\end{array}$ & \\
\hline $0-3$ & 15,15 & $3,2.91$ & \multirow{3}{*}{$<0.001$} \\
\hline $4-6$ & 24,24 & $10,9.71$ & \\
\hline $7-10$ & 61,61 & $90,87.38$ & \\
\hline \multicolumn{3}{|c|}{ NICU admission } & \multirow{4}{*}{$<0.001$} \\
\hline Yes & 37,37 & 12,12 & \\
\hline No & 63,63 & 88,88 & \\
\hline Perinatal death & $(n=103)$ & $(n=103)$ & \\
\hline Yes & $8,7.77$ & $2,1.94$ & \multirow{2}{*}{0.052} \\
\hline No & $95,92.23$ & $101,98.06$ & \\
\hline
\end{tabular}

\section{DISCUSSION}

Present study was done to compare the labour and perinatal outcome in cases of oligohydramnios with normal pregnancy. Although well documented in literature, management of patients with low AFI still haunts obstetricians.

The labour and perinatal effects are varied and can lead to diverse complications needing a multidisciplinary approach to management. In the present study, mean age of the patients in case were 21.71845 years, reflecting the child bearing age of most of the women with the mean $( \pm$ SD) maternal age of $22.8 \pm 4.2$ years. Similar studies by Chauhan $\mathrm{P}$ et al, Jun Zhang et al, Bangal et al and Guin et al found that the mean maternal age were 23.6 \pm 6.5 years, $28.4 \pm 3.4$ years, $22.8 \pm 4.2$ years and $24.71 \pm 4.58$ years respectively. ${ }^{14}$ Similar to the studies by Manzanares $S$ et al and Bhattacharya R, incidence of low AFI was higher in unbooked cases reflecting the need for close antenatal surveillance in these patients. ${ }^{15,16}$ In present study, $67 \%$ of patients in the study group were primaegravida.

This is in contrast to the study by Bhattacharya $\mathrm{R}$ et al where they found only $31 \%$ patients were primaegravid in the low AFI group. Present study found that there is increase rate of induction of labour in study group $(48.54 \%)$. A study by Casey B et al found that there was increased rate of induction of labour (42\%) in oligohydramnios cases.

Authors also found that there is increased incidence of caesarean section rate in induction group (74\%) when compared to control group. Jun Zhang et al. found that, the overall caesarean delivery rates were similar between women with oligohydramnios and the controls (24\% vs. $19 \%) .^{17}$

The number of patients with moderate and thick meconium staining of liquor were markedly more in the case group compared to the control ( $44.67 \%$ vs $3.9 \%$ ). This is in contrast to a previous study 18 where it was just slightly more $(8 \%$ vs $6 \%) .{ }^{18}$ In present study the incidence of preeclampsia was high $(42.72 \%)$ in the study group. It is an isolated risk factor in the causation of oligohydramnios due to diminished placental perfusion. However, in studies by Bangal et al and Vidyasagar V, incidence was slightly lower at $16 \%$ and $16.28 \%$ respectively. ${ }^{19}$ This study shows the incidence of low birth weight in study group was much higher $(66.99 \%)$ when compared to $(27.18 \%)$ control group. $9.71 \%$ in the study group had birth weight $<2 \mathrm{~kg}$.

This is contrast to the study by Vidyasagar $\mathrm{V}$ where it was $31.7 \%$. In our present study APGAR score at 5 minutes were compared between the study and control groups. $39 \%$ of the cases in study group had APGAR less than 7, compared to $12.62 \%$ of in control group. Desai $\mathrm{P}$ et al 20 found three newborns with Apgar score less than 7 at 5 minutes as against only one in control group. In a similar study by Locatelli A et al of 341 patients with oligohydramnios, found no significant difference for Apgar score of less than 7 at 5 minutes in study and control group. ${ }^{18}$

We found that there is increased incidence of NICU admission in study group $(32.04 \%)$ when com-pared to $(12.62 \%)$ in control group. This difference was statistically significant. Sriya $\mathrm{R}$ et al found this to be as high as $88.88 \%$. Bhattacharya $\mathrm{R}$ also found NICU admission much higher at $65 \% .^{21}$

Present study showed still birth was $2.91 \%$ in the study group while nil in the control group. Perinatal death was $7.77 \%$ in the case group compared to in $1.94 \%$ in the control group. Chhabra $\mathrm{S}$ et al reported very high $(87.7 \%)$ perinatal mortality in their study. Apel Sarid L et al found that the perinatal mortality was $9.9 \% .^{22,23}$

\section{CONCLUSION}

Oligohydramnios is a common disorder found in obstetric units due to its wide range of etiologies. Early diagnosis, correction of underlying pathology and preventing fetal and perinatal mortality and morbidity are the obstetric goals. Various previous studies have looked at fetomaternal outcomes.

Present study shows that there is a definite statistically significant relation between low AFI and adverse labour and fetoperinatal outcomes. Individualisation of treatment strategies and subsequent termination can reduce complications and disease burden. 


\section{ACKNOWLEDGMENTS}

Authors would like to thank the staff and residents of the Department of Obstetrics and Gynaecology, Burdwan Medical College and Hospital in conducting this trial.

Funding: No funding sources

Conflict of interest: None declared

Ethical approval: The study was approved by the Institutional Ethics Committee

\section{REFERENCES}

1. Cunningham FG, Leveno KJ, Bloom SL, Spong CY, Dashe JS, Hoffman BL et al. Amnionic Fluid.I n : Cunningham FG et al. Williams Obstetrics.24th ed. New York, USA: McGraw Hill Education; 2014.231-9

2. Guin G, Punekar S, Lele A, Khare. A Prospective Clinical Study of Feto Maternal Outcome in Pregnancies with Abnormal Liquor Volume. J Obstet Gynaecol India. 2011;61(6):652-5.

3. Antepartum fetal surveillance. Practice Bulletin No. 145. American College of Obstetricians and Gynecologists. Obstet Gynecol. 2014;124(1):182-92,

4. Zhang J, Troendle J, Meikle S, Klebanoff MA, Rayburn WF. Isolated oligohydramnios is not associated with adverse perinatal outcomes. Br J Obstet Gynaecol. 2004;111(3):220-5.

5. Phelan JP, Smith CV, Small M. Amniotic fluid volume assessment with four quadrant technique at 36-42 weeks of gestation. J Reproduct Med. 1987;32(7):540-2.

6. Dutta DC. Multiple Pregnancy, Hydramnios and Anormalities of Placenta and Cord.In: Konar H. 7th edition. Textbook of Obstetrics.New Delhi : Jaypee Brothers Medical Publishers (P) Ltd; 2013:200-18.

7. Chauhan SP, Washburne JF, Magann EF. A randomized study to assess the efficacy of the amniotic fluid index as a fetal admission test. Obstet Gynecol. 1995;86(1):9.

8. Sultana S, Khan MAK, Akhtar KAK, Aslam M. Low amniotic fluid index in high risk pregnancy and poor Apgar score at birth. J College Physicians Surgeons Pakistan. 2008;18(10):630-4.

9. Ahmad H, Munim S. Isolated Oligohydramnios is not an indicator for adverse perinatal outcome. J Pak Med Asso. 2009;59(10):691.

10. WMA Declaration of Helsinki - Ethical Principles for Medical Research Involving Human Sub-jects. France: World Medical Association, Inc. Available from: https://www.wma.net/policies-post/wmadeclaration-of-helsinki-ethical-principles-formedical-research-involving-human-subjects/

11. Leduc D, Biringer A, Lee L, Dy J. Induction of labour linical practice guide-line. SOGC. J Obstet Gynaeco Can. 2013;35(9):840-57.
12. Smith JG, Merrill DC. Oxytocin for induction of labor. Clin Obstet Gynecol 2006;49(3):594-608.

13. ACOG Practice Bulletin 107, Aug 2009Available at https://www.acog.org/Clinical-Guidance-andPublications/Practice-Bulletins/Committee-onPractice-Bulletins-Obstetrics/Induction-of-Labor

14. Bangal VB, Purushottam AG, Bhushan MS. Incidence of oligohydramnios during pregnancy and its effects on maternal and perinatal outcome. J Pharma Biomed Sci. 2011;12(12):5.

15. Manzanares S, Carrillo MP, Gonzalez-Peran E, Puertas A, Montoya F. Isolated oligohydram-nios in term pregnancy as an indication for induction of labour. J Matern Fetal Neonatal Med. 2007;20(3):221-4.

16. Bhattacharya R, Akshaya S. Fetomaternal outcome in patients with oligohydromnions in a ter-tiary hospital. Int J Reprod Contracept Obstet Gynecol. 2016;5(8):2576-80.

17. Casey BM, Donald DM, Bloom SL, Lucas MJ, Santos R, Twickler DM et a; Pregnancy outcomes after antepartum diagnosis of oligohydramnios at or beyond 34 weeks' gestation. Am J Obstet Gynecol. 2000;182(4):909-12.

18. Locatelli A, Vergani P, Toso L, Verderio M, Pezzullo JC. Perinatal outcome associated with oligohydramnios in uncomplicat-ed term pregnancies. Arch Gynecol Obstet. 2004; 269(2):130-3.

19. Vidyasagar V, Chutani N. Fetomaternal outcome in cases of oligohydramnios after 28 weeks of pregnancy. Int J Reprod Contracept Obstet Gynecol 2015;4(1):152-6.

20. Desai Pankaj, Patel purvi, Gupta Anjali. Decreased amniotic fluid index in low risk pregnancy: any significance? J Obstet Gynecol Ind Vol 54, No.5: September/October 2004; 54(5):464-6.

21. Sriya R, Singhai S. Perinatal outcome in patients with amniotic fluid index $<5 \mathrm{~cm}$. J Obstet Gynaecol India. 2001;51:98-100.

22. Chhabra S, Dargan R. Oligohydramnios - a potential marker for serious obstetric complications. J Obstet Gynecol. 2007;27(7):680-3.

23. Apel-Sarid L, Levy A, Holcberg G, Sheiner E. Placental pathologies associated fetal growth restriction complicated with and without oligohydramnios. Arch Gynecol Obstet. 2009:280(4);126-30.

Cite this article as: Mandi D, Sen S, Goswami V. A prospective case control study of the effects of oligohydramnios on fetomaternal outcome in mothers with term pregnancy in a rural medical college. Int $\mathbf{J}$ Reprod Contracept Obstet Gynecol 2018;7:4706-10. 